\title{
Synergistic Flame Retardancy of Aluminium Dipropylphosphinate and Melamine in Polyamide 6
}

\author{
Linsheng Tang, Zhigang Yuan, Lu Xu, Xue Li, and Yuzhen Ge \\ College of Chemical Engineering, Qingdao University of Science and Technology, Qingdao 266042, China \\ Correspondence should be addressed to Linsheng Tang; linshengt62@163.com
}

Received 21 May 2013; Accepted 24 September 2013

Academic Editor: William A. Jesser

Copyright ( 2013 Linsheng Tang et al. This is an open access article distributed under the Creative Commons Attribution License, which permits unrestricted use, distribution, and reproduction in any medium, provided the original work is properly cited.

\begin{abstract}
The synergistic flame retardancy of aluminium dipropylphosphinate (ADPP) and melamine (ME) in polyamide 6 (PA6) was studied by the limiting oxygen index (LOI) measurement, the vertical burning test, and the cone calorimeter test, and the mechanism was also discussed by thermogravimetric and residual analyses. The experimental results indicated that there was obvious synergistic flame retardancy between ADPP and ME under their appropriate weight ratios. The thermogravimetric results and the analysis of the residues obtained in cone calorimeter test showed that ADPP and ADPP/ME played the role of flame retardance by gaseous- and condensed-phase mechanisms, where, on one hand, they were decomposed into nonvolatile aluminum phosphate and promoted the carbonization of PA6, and the formed intumescent layer resulted in flame retardancy by the barrier effect on heat, air, and decomposition products, and on the other hand, they were decomposed into volatile phosphorus compounds which bring about flame retardancy by flame inhibition. Using a combination of ADPP and ME improved charring of PA6 and raised the residual rate of $\mathrm{P}$ and $\mathrm{Al}$, thus, improving the barrier effect in the condensed phase.
\end{abstract}

\section{Introduction}

The alkylphosphinates developed by Clariant Company (Germany) belong to a novel class of phosphorous flame retardants. The alkylphosphinates have some merits such as low toxicity and smoke density, high comparative tracking index (CTI), good thermal stability, and being especially used as flame retardants for polyamides, polyesters, and epoxy resins [1]. Some patents reported that alkylphosphinates and nitrogen flame retardants such as melamine derivatives had obvious synergistic flame retardancy in polyamides [2-6]. However, so far, only very little literatures reported the flame retardancy mechanism and regularity $[7,8]$, so there is a lack of scientific understanding as to the synergistic flame retardancy regularity and mechanism between alkylphosphinates and nitrogen flame retardants. Thus, the flame retardancy and its mechanisms of aluminium dipropylphosphinate in combination with melamine in polyamide 6 was illumianated in this paper.

\section{Experimental}

2.1. Materials. Nylon 6 (PA6) was provided by Shijiazhuang Refining \& Chemical Co., China. The aluminium dipropylphosphinate (ADPP) was made by ourselves. The melamine was provided by Wujiang City Today Chemical Technology Co., Ltd., China. The antioxidants of 1010 and 168 were provided by Beijing Jiyi Chemical Co., Ltd., China. All materials used in this work were of technical grade and were used without further purification.

2.2. Preparation of Flame-Retarded Samples. PA6, flame retardants, and small amounts of 1010 and 168 antioxidants were mixed at about $230^{\circ} \mathrm{C}$ in a JS30A twin-screw extruder (YanTai City Qitong Machinery Co., Ltd., China.) with a rotor speed of 20 30 rpm. The well-mixed ingredients were cooled to ambient temperature and were mould-pressed into $100 \times 100 \times 4 \mathrm{~mm}$ sheets at $220^{\circ} \mathrm{C} 230^{\circ} \mathrm{C}$ under $5 \mathrm{MPa}$ by 2G-10T press vulcanizer (Dongguan Zhenggong Mechanical 
and Electrical Equipment Technology Co., Ltd., China). The sheets were then cut into standard samples $\left(100 \times 13 \times 4 \mathrm{~mm}^{3}\right.$ and $100 \times 6.5 \times 4 \mathrm{~mm}^{3}$ ) for flame retardant test.

2.3. Flame Retardant Test. Limiting oxygen index (LOI) was measured according to ASTM D 2863 with a JF-3 oxygen index meter (Jiangning Analytical Instrument Company, China). The specimens used for the LOI test were of dimensions of $100 \times 6.5 \times 4 \mathrm{~mm}^{3}$.

The vertical burning test was carried out on CZF-3 horizontal and vertical burning tester (Jiangning Analytical Instrument Company, China) with specimens of $100 \times 13 \times$ $4 \mathrm{~mm}^{3}$ according to the UL 94 test standard.

The fire behavior of PA6 and flame-retarded PA6 for flaming conditions was characterized according to ISO5660 using an FTT standard cone calorimeter (FTT Company, UK) in external heat fluxes of $50 \mathrm{kw} / \mathrm{m}^{2}$ with specimens of $100 \times$ $100 \times 4 \mathrm{~mm}^{3}$. This method enabled investigation with respect to heat release rate (HRR), total heat release (THR), and mass loss rate (MLR).

2.4. Thermogravimetric Analysis. Thermogravimetric (TG) experiments were performed using SDT Q600 thermogravimetric analyzer (TA Company, USA) with a heating rate of $10^{\circ} \mathrm{C} / \mathrm{min}$ and nitrogen flow of $50 \mathrm{~mL} / \mathrm{min}$.

2.5. Characterization of the Residue. The surface morphology of the residue obtained in the cone calorimeter test was observed by scanning electron microscopy (SEM, Model JSM-6700F Jeol, Japan).

IR spectra of the residue were measured by potassium bromide pellet technology using a TENSOR-27 IR spectrometer (Bruker Corporation, Germany).

${ }^{31} \mathrm{P}$ NMR spectra were acquired with an Advance 500 spectrometer (Bruker Corporation, Germany) with $\mathrm{D}_{2} \mathrm{O}$ as a solvent, and ${ }^{31} \mathrm{P}$ chemical shifts were referenced to phosphoric acid $(\delta=0 \mathrm{ppm})$.

The content of nitrogen was measured by the method of Kjeldahl nitrogen determination [9].

The content of phosphorous was measured by the method of gravimetric quimociac method [10].

The content of aluminum was measured by the EDTA titration method [11].

\section{Results and Discussion}

3.1. The LOI and Vertical Burning Property. As the loading of flame retardants was $25 \mathrm{wt} \%$ based on the total weight of the composites, effect of the formulation of the combinations of ADPP and ME was investigated. As could be seen in Table 1, the weight ratios of ADPP to ME had significant impact on the LOI and vertical burning property of the flame-retarded PA6. The LOI of the flame-retarded PA6 increased firstly with the increase of the proportion of $\mathrm{ME}$, and as the weight ratios of ADPP to Me were $75: 25 \sim 45: 55$, the LOI changed slightly then decreased with the increasing ratios of ME. However, there was not obvious influence of the proportion of $\mathrm{ME}$ on the UL 94 classification; all samples reached FV-0 class during 100:0 25:75 of the weight ratios of ADPP to ME. The LOI of the flame-retarded PA6 alone with ADPP could be up to $33.2 \%$, and the demanding V-0 classification of the burning test could be achieved, while the LOI of the flameretarded PA6 with ME was $28.3 \%$, and any classification of the burning test could not be reached, which revealed that the flame retardancy of ADPP was markedly better than that of ME in PA6.

In order to further confirm the synergistic flame retardancy between ADPP and ME, the effect of the loading of flame retardants on the LOI and vertical burning property of the flame-retarded PA6 was, respectively, investigated under $100: 0,75: 25,25: 75$, and $0: 100$ of the weight ratios of ADPP to $\mathrm{ME}$, and the results were shown in Table 2.

As could be seen in Table 2, the LOI of PA6 without flame retardant was $22.5 \%$, and any classification could not be reached. The LOI of the flame-retarded PA6 alone with $15 \mathrm{wt} \%$ of the loading of ADPP could be up to $30.7 \%$, and the demanding V-0 classification of the burning test could be achieved, which indicated that ADPP had good flame retardancy in PA6. As the weight ratio of ADPP to ME was $75: 25$ and the loading of the combination was $10 \mathrm{wt} \%$ based on the total weight of the composites, the LOI of the flameretarded PA6 could be up to $30.9 \%$, and the demanding V-0 classification of the burning test could be achieved. However, as the weight ratio of ADPP to ME was $25: 75$, only when the dosage of the combination is $25 \mathrm{wt} \%$, the demanding $\mathrm{V}-0$ classification could be achieved. The LOI of the flameretarded PA6 alone with $25 \mathrm{wt} \%$ of the dosage of ME was $28.3 \%$, and any classification could not be reached, which indicated that ME had poor flame retardancy in PA6. Thus, it could be seen that there was obvious synergistic flame retardancy between ADPP and ME under their appropriate weight ratios.

3.2. Fire Behavior: Heat Release and Mass Loss. HRR, MLR, and THR of PA6 and the flame-retarded PA6 were, respectively, illustrated in Figures 1, 2, and 3. It could be clearly seen that the HRR, MLR, and THR of PA6 increased rapidly after ignition; the curve of HRR was characterized by a sharp peak with $1013 \mathrm{kw} / \mathrm{m}^{2}$ of maximum heat release rate in the burning of $194 \mathrm{~s}$; PA6 was burned perfectly in $450 \mathrm{~s}$. Compared with PA6, the HRR, MLR, and THR of the flameretarded PA6 alone with $25 \mathrm{wt} \%$ of the loading of ME also increased rapidly after ignition, but its curve of HRR was sharper with $1119 \mathrm{kw} / \mathrm{m}^{2}$ of maximum heat release rate in the burning of $185 \mathrm{~s}$, and it was burned perfectly in $345 \mathrm{~s}$, which revealed no flame retardancy of ME. The HRR, MLR and THR of the flame-retarded PA6 alone with $25 \mathrm{wt} \%$ of the loading of ADPP increased slowly after ignition; the curve of HRR was characterized by a wider peak; the maximum heat release rate and mass lose rate reduced markedly; the heat release rate was maintained at $200-469 \mathrm{kw} / \mathrm{m}^{2}$ during the burning of $115 \mathrm{~s}-445 \mathrm{~s}$; the time for complete combustion was $550 \mathrm{~s}$, but the total heat release increased slightly, which suggested slower combustion. The HRR, MLR, and THR curves of the flame-retarded PA6 with $25 \mathrm{wt} \%$ of dosage of 
TABLE 1: Effect of the weight ratios of ADPP to Me on its flame retardance in PA6.

\begin{tabular}{lccc}
\hline$w(\mathrm{ADPP}): w(\mathrm{ME})$ & LOI/\% & UL 94 class & Combustion phenomenon \\
\hline $100: 0$ & 33.2 & FV-0 & FV-0 \\
$85: 15$ & 35.4 & FV-0 & Difficult ignition, self-extinguishing, no drips \\
$75: 25$ & 36.3 & FV-0 & Difficult ignition, self-extinguishing, nolf-extinguishing, no drips \\
$65: 35$ & 36.4 & FV-0 & Difficult ignition, self-extinguishing, no drips \\
$55: 45$ & 36.5 & FV-0 & Difficult ignition, self-extinguishing, no drips \\
$45: 55$ & 36.6 & FV-0 & Difficult ignition, self-extinguishing, no drips \\
$35: 65$ & 35.2 & FV-0 & Difficult ignition, self-extinguishing, no drips \\
$25: 75$ & 34.0 & FV-1 & Difficult ignition, self-extinguishing, no drips \\
$15: 85$ & 31.1 & - & Gentle combustion, self-extinguishing, no drips \\
$0: 100$ & 28.3 & & Sustained combustion, later severe, drips \\
\hline
\end{tabular}

TABLE 2: Effect of the loading of flame retardants on its flame retardance in PA6.

\begin{tabular}{|c|c|c|c|c|}
\hline$w(\mathrm{ME}): w(\mathrm{ADPP})$ & Loading/\% & $\mathrm{LOI} / \%$ & UL 94 class & Combustion phenomenon \\
\hline \multirow{6}{*}{$0: 100$} & 0 & 22.5 & - & Sustained combustion, drips \\
\hline & 5 & 26.8 & - & Sustained combustion, drips \\
\hline & 10 & 29.8 & FV-1 & Gentle combustion, self-extinguishing, no drips \\
\hline & 15 & 30.7 & $\mathrm{FV}-0$ & Difficult ignition, self-extinguishing, no drips \\
\hline & 20 & 32.2 & $\mathrm{FV}-0$ & Difficult ignition, self-extinguishing, no drips \\
\hline & 25 & 33.2 & FV-0 & Difficult ignition, self-extinguishing, no drips \\
\hline \multirow{5}{*}{$25: 75$} & 5 & 28.7 & - & Sustained combustion, drips \\
\hline & 10 & 30.9 & $\mathrm{FV}-0$ & Difficult ignition, self-extinguishing, no drips \\
\hline & 15 & 31.8 & $\mathrm{FV}-0$ & Difficult ignition, self-extinguishing, no drips \\
\hline & 20 & 34.7 & FV-0 & Difficult ignition, self-extinguishing, no drips \\
\hline & 25 & 36.3 & FV-0 & Difficult ignition, self-extinguishing, no drips \\
\hline \multirow{5}{*}{$75: 25$} & 5 & 28.0 & - & Sustained combustion, drips \\
\hline & 10 & 28.8 & - & Sustained combustion, drips \\
\hline & 15 & 29.8 & - & Sustained combustion, drips \\
\hline & 20 & 30.3 & FV-1 & Gentle combustion, self-extinguishing, no drips \\
\hline & 25 & 34.0 & FV-0 & Difficult ignition, self-extinguishing, no drips \\
\hline \multirow{5}{*}{$100: 0$} & 5 & 23.5 & - & Sustained combustion, drips \\
\hline & 10 & 24.1 & - & Sustained combustion, drips \\
\hline & 15 & 26.7 & - & Sustained combustion, drips \\
\hline & 20 & 27.6 & - & Sustained combustion, drips \\
\hline & 25 & 28.3 & - & Sustained combustion, drips \\
\hline
\end{tabular}

$\mathrm{ADPP} / \mathrm{ME}$ (the weight ratio of $\mathrm{ADPP} / \mathrm{ME}$ was $75: 25$ ) were similar with those of the aforementioned flame-retarded PA6 with ADPP, but the maximum heat release rate and mass lose rate of the former were smaller, HRR curve was broader, and the time for complete combustion was longer, which further confirmed synergistic flame retardancy between ADPP and ME in PA6.

3.3. Fire Retardancy Mechanisms. The flame retardancy mechanism of ADPP/ME in PA6 was discussed by the residual analysis and thermogravimetric analysis of the flame retardants and the flame-retarded PA6.

3.3.1. Thermogravimetric Analysis. Thermogravimetric results of flame-retardants and flame retarded PA6 were presented in Figures 4, 5, 6, and 7 and Table 3. As could be seen in Figure 4 and Table 3, the initial thermal decomposition temperatures (the temperature for $2 \%$ of mass loss) of ADPP and $\mathrm{ME}$ were, respectively, $315.8^{\circ} \mathrm{C}$ and $237.6^{\circ} \mathrm{C}$, and subsequently the mass loss of ADPP was smaller than that of ME under the same temperature. The complete thermolysis temperatures of ADPP and $\mathrm{ME}$ were, respectively, $500^{\circ} \mathrm{C}$ and $325^{\circ} \mathrm{C}$, and their mass percentages of the resulting residues under the above temperatures were, respectively, about $14 \mathrm{wt} \%$ and $0 \mathrm{wt} \%$, which was because ADPP was decomposed into nonvolatile aluminum phosphate, while $\mathrm{ME}$ was decomposed into volatile $\mathrm{N}_{2}$ and $\mathrm{CO}_{2}$. The initial thermal decomposition temperature of $75 \mathrm{wt} \% \mathrm{ADPP} / 25 \mathrm{wt} \% \mathrm{ME}$ was $230.7^{\circ} \mathrm{C}$, and the decomposition temperatures for $5 \%$ and $10 \%$ of mass loss were, respectively, $248.1^{\circ} \mathrm{C}$ and $262.6^{\circ} \mathrm{C}$, obviously lower than those of ADPP and ME for the same mass loss. 


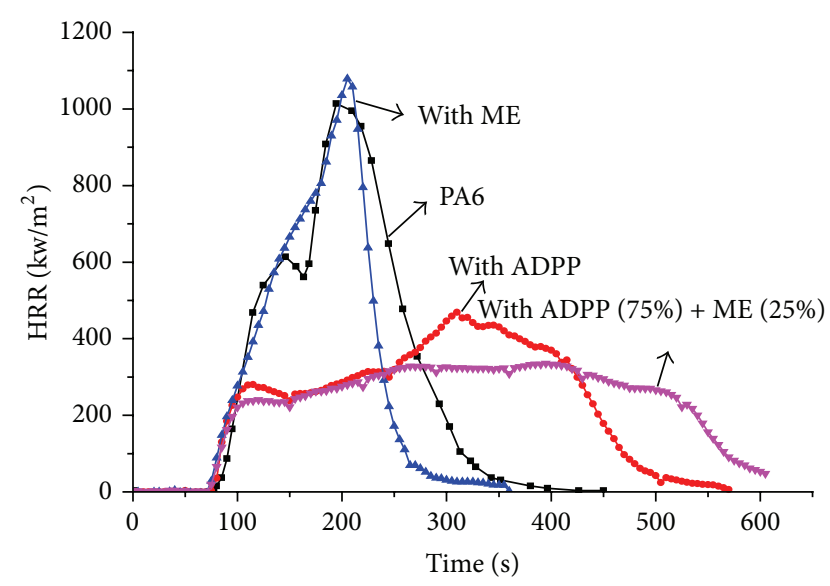

FIgURE 1: HRR curves of PA6 and flame-retarded PA6.

However, when the mass loss was more than about $20 \%$, the decomposition temperature of $75 \% \mathrm{ADPP} / 25 \% \mathrm{ME}$ was between ADPP and ME, and the mass loss of the ADPP/ME was larger than their additive value (supposing no interaction between $\mathrm{ADPP}$ and $\mathrm{ME}$ ), below $370^{\circ} \mathrm{C}$ and over $440^{\circ} \mathrm{C}$, while the results come over in the range of $320^{\circ} \mathrm{C}$ to $420^{\circ} \mathrm{C}$, which implied that there was an obvious interaction between ADPP and ME and that ADPP and ME could promote mutually the decomposition below $370^{\circ} \mathrm{C}$ and over $440^{\circ} \mathrm{C}$ but could retard mutually the decomposition in the range of $320^{\circ} \mathrm{C}$ to $420^{\circ} \mathrm{C}$.

As could be seen in Figure 5 and Table 3, PA6 was initially decomposed in $333.9^{\circ} \mathrm{C}$ (the temperature for $2 \%$ mass loss), rapidly over $402.6^{\circ} \mathrm{C}$, and almost completely in $490^{\circ} \mathrm{C}$ without any residue, which meant that PA6 was extremely difficult to be carbonized. The flame-retarded PA6 with $25 \mathrm{wt} \%$ of ADPP was initially decomposed in $309.7^{\circ} \mathrm{C}$, and the decomposition temperatures for $5 \%$ and $10 \%$ of mass loss were, respectively, $328.4^{\circ} \mathrm{C}$ and $346.9^{\circ} \mathrm{C}$, obviously lower than those of PA6 with the same mass loss, which suggested that the addition of ADPP cut down the thermal stability of PA6. Compared with the additive curves of 75\% PA6 and 25\% ADPP (supposing no interaction between PA6 and ADPP), the mass loss of the flame-retarded PA6 with ADPP was larger and significantly below $470^{\circ} \mathrm{C}$, which indicated that there was a mutually promoted decomposition between PA6 and ADPP but contrariy over $470^{\circ} \mathrm{C}$ and that the residual rate in $700^{\circ} \mathrm{C}$ was $23 \%$, indicating improved charring of PA6 by ADPP.

It could be seen from Figure 6 and Table 3 that the decomposition temperatures of the flame-retarded PA6 with $25 \mathrm{wt} \%$ of ME for $2 \%, 5 \%$, and $10 \%$ of mass loss were, respectively, $268.9^{\circ} \mathrm{C}, 313.5^{\circ} \mathrm{C}$, and $345.9^{\circ} \mathrm{C}$, obviously lower than those of the flame-retarded PA6 with $25 \mathrm{wt} \%$ of ADPP under the same mass loss, which suggested that the addition of ME reduced more seriously the thermal stability of PA6 than ADPP.

The mass loss of the flame-retarded PA6 with ME was lower than the additive values below $400^{\circ} \mathrm{C}$, which implied that there was a mutual stabilization between PA6 and ME but contrariy from $400^{\circ} \mathrm{C}$ to $480^{\circ} \mathrm{C}$ and that the residual rate in $500^{\circ} \mathrm{C}$ was $18 \%$, indicating improved charring of PA6 by ME.

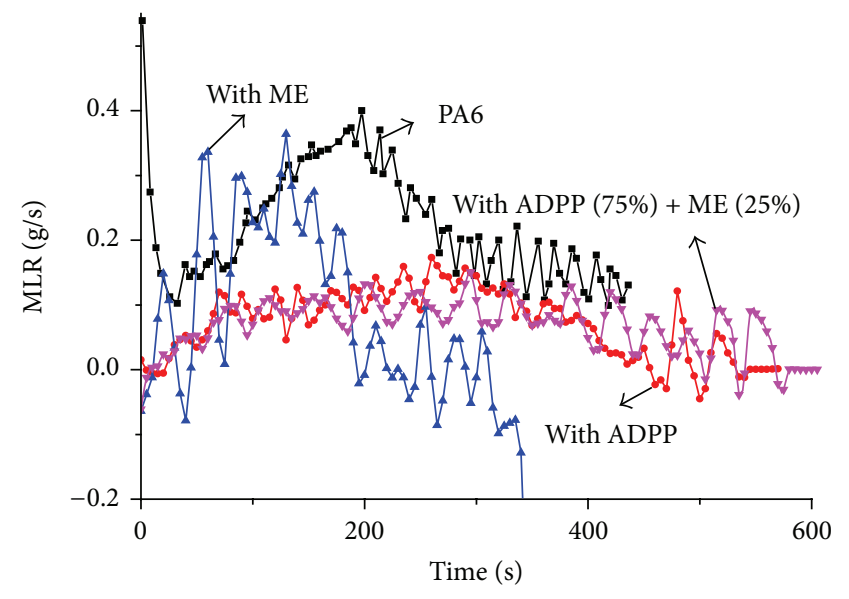

Figure 2: MLR curves of PA6 and flame-retarded PA6.

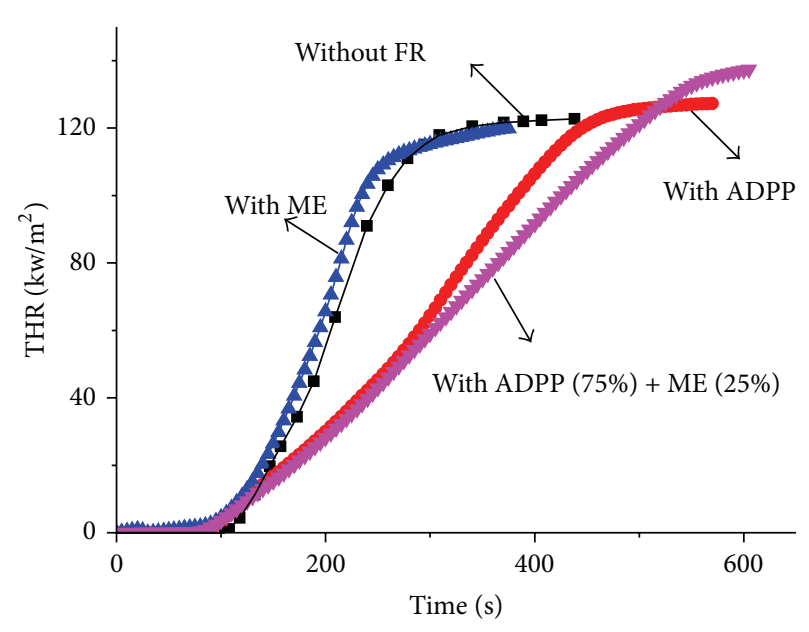

Figure 3: THR curves of PA6 and flame-retarded PA6.

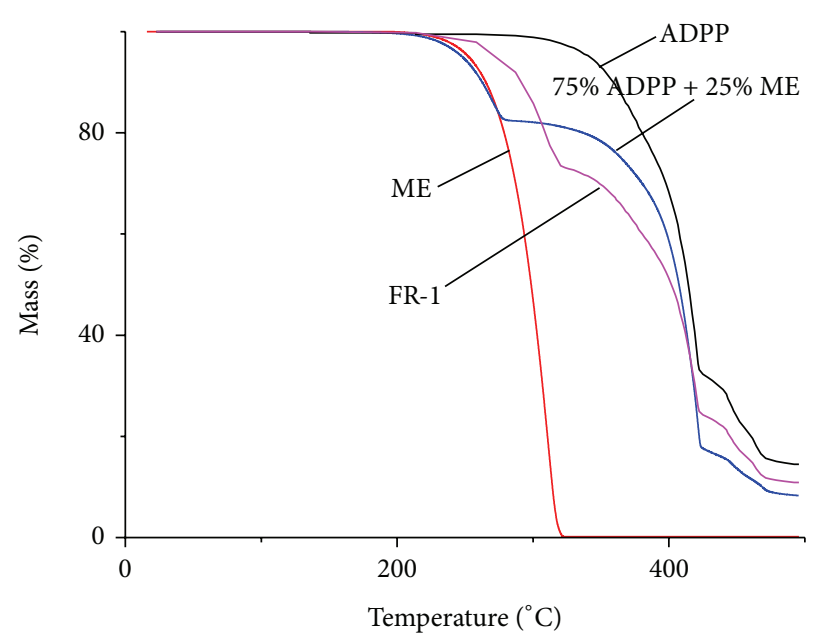

FIGURE 4: TG of ADPP, ME, and the combination of ADPP/ME. FR1: additive curve of $75 \% \mathrm{ADPP}$ and $25 \% \mathrm{ME}$. 
TABle 3: Thermogravimetric results.

\begin{tabular}{|c|c|c|c|c|}
\hline \multirow{2}{*}{ Materials } & \multicolumn{4}{|c|}{ Mass loss } \\
\hline & $2 \% /{ }^{\circ} \mathrm{C}$ & $5 \% /{ }^{\circ} \mathrm{C}$ & $10 \% /{ }^{\circ} \mathrm{C}$ & $50 \% /{ }^{\circ} \mathrm{C}$ \\
\hline PA6 & $333.6^{\circ} \mathrm{C}$ & $386.1^{\circ} \mathrm{C}$ & $402.6^{\circ} \mathrm{C}$ & $450.1^{\circ} \mathrm{C}$ \\
\hline ADPP & 315.8 & 342.3 & 358.8 & 413.6 \\
\hline ME & 237.6 & 252.7 & 265.3 & 298.5 \\
\hline $\mathrm{ADPP} / \mathrm{ME}^{*}$ & 230.7 & 248.1 & 262.6 & 407.4 \\
\hline Flame-retarded PA6 with 25 wt $\%$ ADPP & $309.7^{\circ} \mathrm{C}$ & $328.4^{\circ} \mathrm{C}$ & $346.9^{\circ} \mathrm{C}$ & $445.0^{\circ} \mathrm{C}$ \\
\hline Flame-retarded PA6 with 25 wt $\%$ ME & $268.9^{\circ} \mathrm{C}$ & $313.5^{\circ} \mathrm{C}$ & $345.9^{\circ} \mathrm{C}$ & $418.5^{\circ} \mathrm{C}$ \\
\hline Flame-retarded PA6 with $25 \mathrm{wt} \%$ ADPP/ME* & $241.3^{\circ} \mathrm{C}$ & $317.2^{\circ} \mathrm{C}$ & $349.2^{\circ} \mathrm{C}$ & $443.4^{\circ} \mathrm{C}$ \\
\hline
\end{tabular}

${ }^{*}$ Mass ratio of ADPP/Me was 75/25.

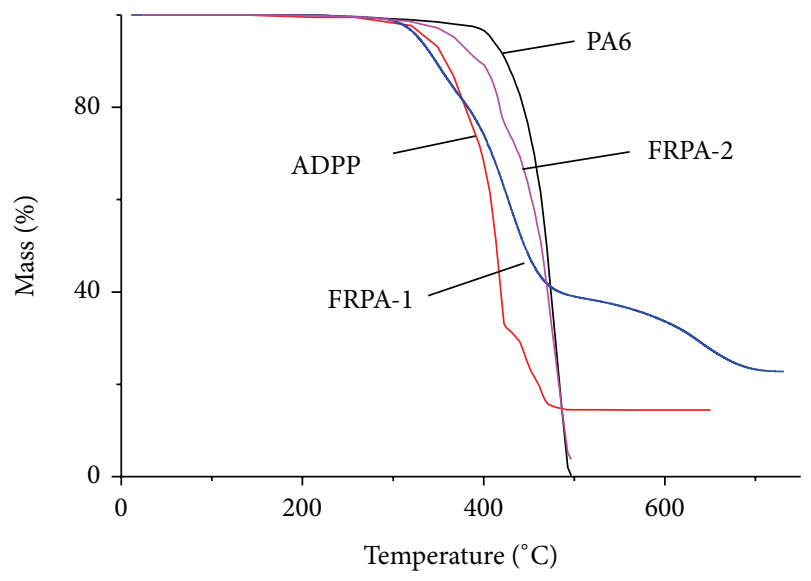

FIGURE 5: TG of the flame-retarded PA6 with ADPP. FRPA-1: flameretarded PA6 with $25 \mathrm{wt} \%$ of ADPP; FRPA-2: additive curve of $75 \%$ PA6 and 25\% ADPP.

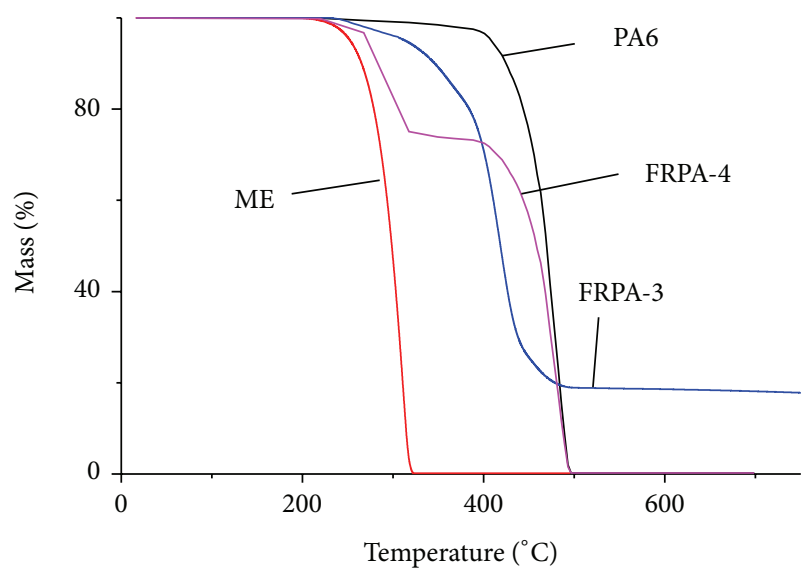

FIGURE 6: TG of the flame-retarded PA6 with ME. FRPA-3: flameretarded PA6 with 25 wt $\%$ of ME; FRPA-4: additive curve of $75 \%$ PA6 and $25 \%$ ME.

The decomposition temperatures of the flame-retarded PA6 with $25 \mathrm{wt} \%$ of the combination with $75 / 25$ of the weight ratio of ADPP/ME for $2 \%$ and $5 \%$ mass loss were, respectively, $241^{\circ} \mathrm{C}$ and $317^{\circ} \mathrm{C}$, close to those of the flame-retarded PA6 with $\mathrm{ME}$, while the decomposition temperature for more than
$10 \%$ of mass loss was close to those of the flame-retarded PA6 with ADPP. Thus, it could be seen that ADPP/ME had great impact on the thermal stability of the materials. The mass loss of the flame-retarded PA6 with ADPP/ME was nearly the same as their additive value below 430 , but it was obviously larger in the range of $430^{\circ} \mathrm{C} \sim 490^{\circ} \mathrm{C}$, and the residual rate was also apparently larger than the additive value, which indicated a mutual promoted decomposition between PA6 and $\mathrm{ADPP} / \mathrm{ME}$ and improved charring of PA6 by ADPP/ME.

\subsubsection{Analysis of the Residues Obtained in Cone Calorimeter} Test. As could be seen in the photos of residues obtained in cone calorimeter test shown in Figure 8, the residues of PA6 and the flame-retarded PA6 with ME were obviously less than those of the flame-retarded PA6 with ADPP and ADPP/ME, and the former did not form the intumescent char layer, while the latter did.

The SEM pictures (Figure 9) of the residues obtained in the cone calorimeter showed that the smooth and dense layers were formed after the combustion of the flame-retarded PA6 with ADPP and ADPP/ME, which brought about the flame retardancy by the barrier effect on heat, air, and decomposition products.

As could be seen in Figure 10, the IR spectra of the residue of the flame-retarded PA6 with ADPP were similar to those of ADPP/ME. $1130 \mathrm{~cm}^{-1}(\mathrm{P}=\mathrm{O})$ and $490 \mathrm{~cm}^{-1}(\mathrm{P}-\mathrm{O}$ or $\mathrm{Al}-\mathrm{O})$ were characteristic bands of aluminum phosphate. The band around $1600 \mathrm{~cm}^{-1}$ was attributed to carbon-oxygen signals from PA6 residue.

As could be seen in Figure 11, the ${ }^{31}$ P NMR spectra of the residue of the flame-retarded PA6 with ADPP dissolved with $10 \mathrm{wt} \%$ sodium hydroxide solution were similar to those of $\mathrm{ADPP} / \mathrm{ME}$. The main signal points to a dominant production of sodium phosphate (aluminium phosphate was converted into sodium phosphate in the presence of sodium hydroxide), due to its position at around $6 \mathrm{ppm}$.

The above IR spectra and ${ }^{31} \mathrm{P}$ NMR spectra revealed that ADPP was partially converted into aluminum phosphate in the process of combustion.

The residual rate of samples, the content, and the residual rate of $\mathrm{P}$ and $\mathrm{Al}$ in the residues obtained in the cone calorimeter test were illustrated in Table 4.

As could be seen in Table 4, the residual rate of PA6 and the flame-retarded PA6 with ME was less than 


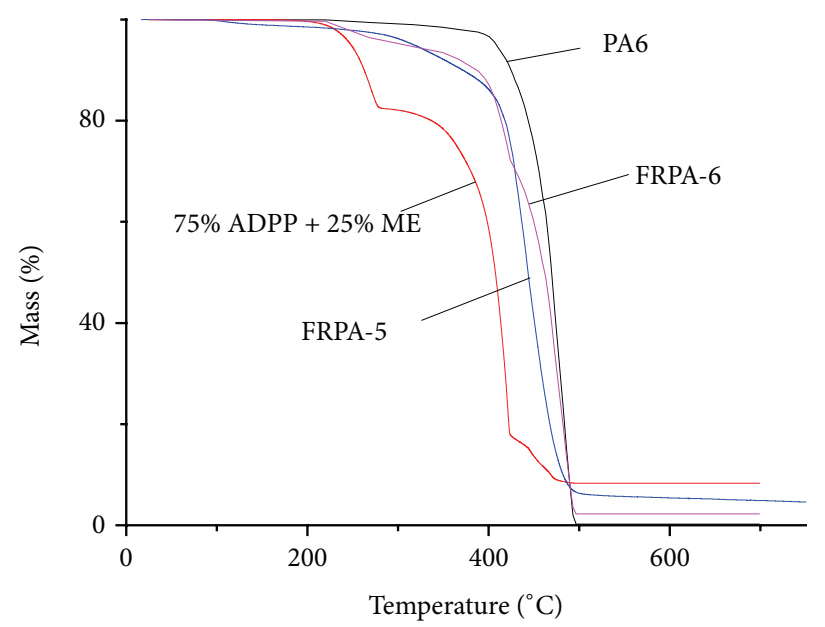

Figure 7: TG of the flame-retarded PA6 with ADPP/ME. FRPA-5: flame-retarded PA6 with 25 wt\% of 75\% ADPP/25\% ME; FRPA-6: additive curve of PA6 and ADPP/ME.

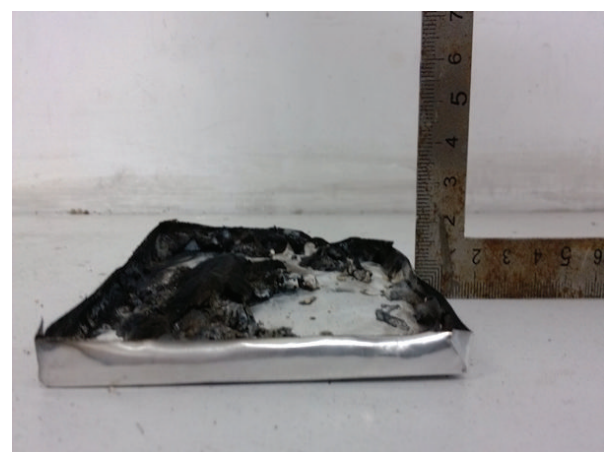

(a)

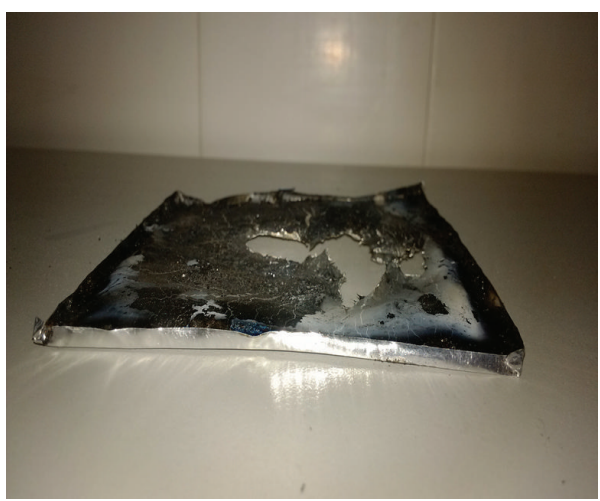

(c)

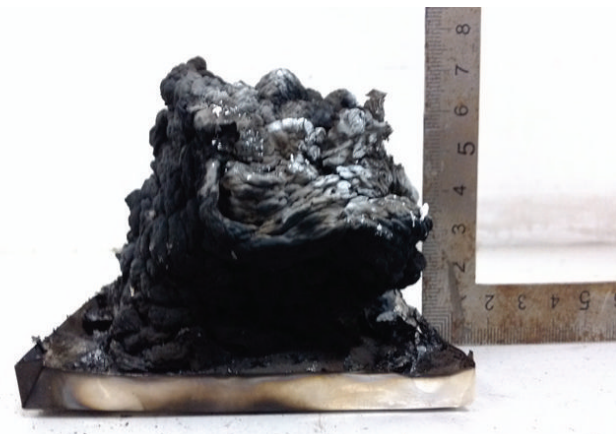

(b)

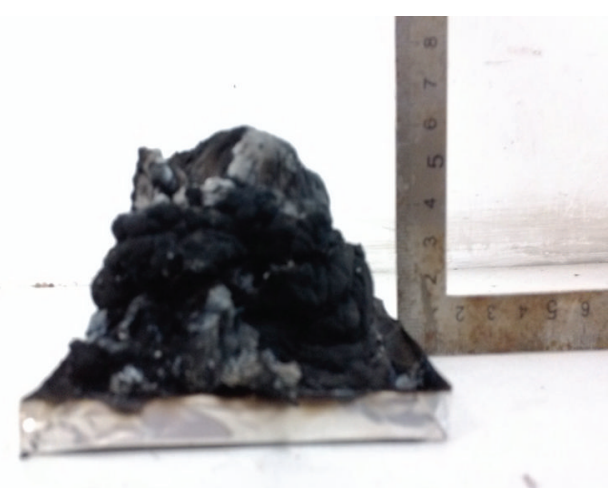

(d)

FIGURE 8: Photos of the residue obtained in the cone calorimeter test: (a) PA6; (b) flame-retarded PA6 with ADPP; (c) flame-retarded PA6 with ME; (d) flame-retarded PA6 with ADPP/ME.

TABLE 4: Analysis results of the residues obtained in the cone calorimeter.

\begin{tabular}{|c|c|c|c|c|c|c|}
\hline \multirow{2}{*}{ Samples } & \multirow{2}{*}{ Residue/\% } & \multicolumn{2}{|c|}{$\mathrm{P}$} & \multicolumn{2}{|c|}{$\mathrm{Al}$} & \multirow{2}{*}{$\mathrm{N} / \%$} \\
\hline & & Content $/ \%$ & Residue/\% & Content $/ \%$ & Residue/\% & \\
\hline PA6 & 0.50 & - & - & - & - & Trace amount \\
\hline Flame-retarded PA6 with ADPP & 3.54 & 18.5 & 13.4 & 14.7 & 36.5 & Trace amount \\
\hline Flame-retarded PA6 with ME & 0.42 & - & - & - & - & Trace amount \\
\hline Flame-retarded PA6 with ADPP/ME & 4.75 & 17.4 & 22.5 & 14.0 & 62.2 & Trace amount \\
\hline
\end{tabular}




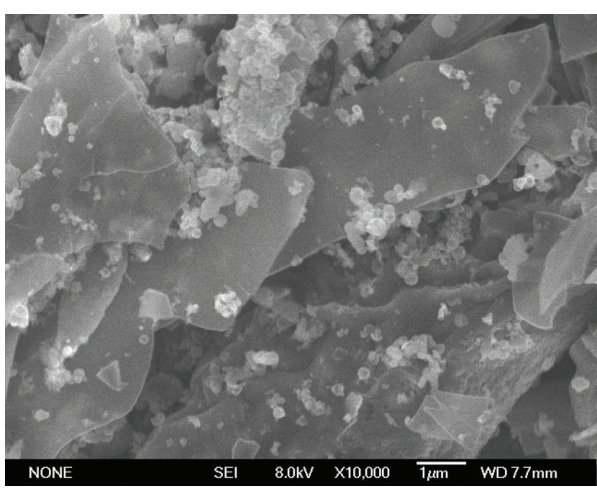

(a)

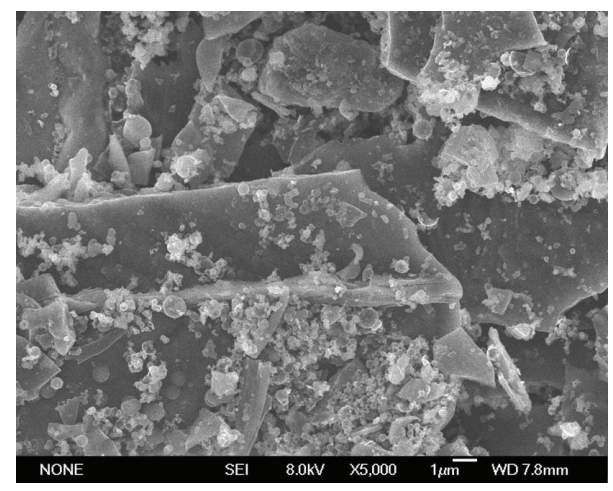

(b)

FIGURE 9: SEM pictures of the residue obtained in the cone calorimeter: (a) flame-retarded PA6 with ADPP; (b) flame-retarded PA6 with ADPP/ME.

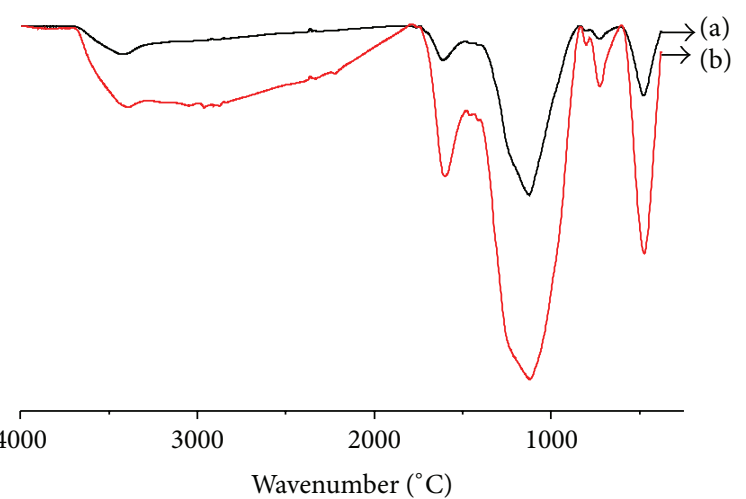

FIGURE 10: IR Spectra of the residues: (a) flame-retarded PA6 with ADPP; (b) flame-retarded PA6 with ADPP/ME.

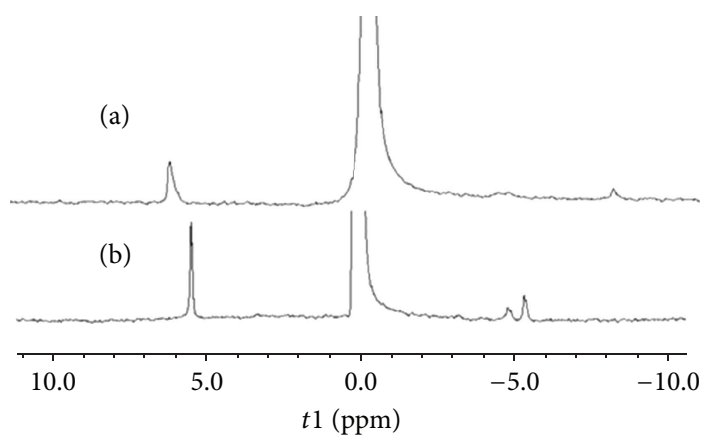

FIGURE 11: ${ }^{31} \mathrm{P}$ NMR of the residues after combustion of: (a) flameretarded PA6 with ADPP/ME; (b) flame-retarded PA6 with ADPP, respectively.

about $0.5 \mathrm{wt} \%$ and was significantly lower than that of the flame-retarded PA6 with ADPP and ADPP/ME, but the latter two were only, respectively, $3.54 \mathrm{wt} \%$ and $4.75 \%$, which indicated that the charring of the flame-retarded PA6 with ADPP and ADPP/ME was better than that of PA6 and the flame-retarded PA6 with ME, but it was not good enough. The above residual rates were conspicuously different from the thermogravimetric results, which might be attributed to the different thermal conditions. The residual rate of $\mathrm{P}$ and $\mathrm{Al}$ in the residues was also lower, which implied that most of the decomposition products of aluminium dipropylphosphinate vaporized to gaseous phase in the process of combustion. Thus, it could be seen that ADPP and ADPP/ME played the flame retardancy by gaseous- and condensed-phase mechanisms, where, on one hand, they were decomposed into nonvolatile aluminum phosphate and promoted the carbonization of PA6, and the formed intumescent layer resulted in flame retardancy by the barrier effect on heat, air, and decomposition products, and on the other hand, they were decomposed into volatile phosphorus compounds which bring about flame retardancy by flame inhibition. Using a combination of ADPP and ME improved charring of $\mathrm{PA} 6$ and raised the residual rate of $\mathrm{P}$ and $\mathrm{Al}$, thus, improving the barrier effect in the condensed phase.

\section{Conclusion}

There was obvious synergistic flame retardancy between ADPP and ME under their appropriate weight ratios. As the weight ratio of ADPP to ME was 75:25 and the loading of the combination is $10 \mathrm{wt} \%$ based on the total weight of the composites, the LOI of the flame-retarded PA6 could be up to $30.9 \%$, and the demanding V-0 classification of the burning test according to the UL 94 standard could be achieved, which were the same as alone with $15 \%$ of the amount of ADPP, but any classification could not be reached alone with $25 \%$ of the amount of ME. Compared with flame-retarded PA6 with ADPP, the maximal heat release rate (HRR) and mass loss rate (MLR) of flame-retarded PA6 with ADPP/ME were smaller, and the curves of HRR-combustion time and MLR-combustion time were broader. The thermogravimetric results and the analysis of the residues obtained in cone calorimeter test showed that ADPP and ADPP/ME played the role of flame retardance by gaseous- and condensed-phase mechanisms, where, on one hand, they were decomposed into nonvolatile aluminum phosphate and promoted the carbonization of PA6, and the formed intumescent layer resulted in flame retardancy by the barrier effect on heat, 
air, and decomposition products, and on the other hand, they were decomposed into volatile phosphorus compounds which bring about flame retardancy by flame inhibition. Using a combination of ADPP and ME improved charring of $\mathrm{PA} 6$ and raised the residual rate of $\mathrm{P}$ and $\mathrm{Al}$, thus, improving the barrier effect in the condensed phase.

\section{Acknowledgment}

This work is financially supported by Shandong Provincial Natural Science Foundation with Grant no. ZR2012BM017.

\section{References}

[1] S. Hörold, B. Naß, O. Schacker et al., A New Generation of Flame Retarded Polyamides Based on Phosphinates, Proceedings of Flame Retardant, Interscience Publisher, London, UK, 2004.

[2] H. Bauer, S. Hoerold, W. Krause et al., "Phosphorus-containing flame retardant agglomerates," US: 7259200 B2. 2007-08-21.

[3] H. Bauer, S. Hoerold, W. Krause et al., "Granular flameretardant composition," US: 7148276 B2. 2006-12-12.

[4] E. Jenewein, H. J. Kleiner, W. Wanzke et al., "Synergistic flame protection agent combination for thermoplastic polymers," US: 6365071 B1. 2002-04-02.

[5] E. Schlosser, B. Nass, W. Wanzke et al., "Flame-retardant combination," US: 6255371 B1. 2001-07-03.

[6] S. Knop, M. Sicken, S. Hoerold et al., "Flame retardant formulation," US: 0014875 A1. 2005-01-20.

[7] U. Braun, B. Schartel, M. A. Fichera, and C. Jäger, "Flame retardancy mechanisms of aluminium phosphinate in combination with melamine polyphosphate and zinc borate in glass-fibre reinforced polyamide 6,6," Polymer Degradation and Stability, vol. 92, no. 8, pp. 1528-1545, 2007.

[8] U. Braun and B. Schartel, "Flame retardancy mechanisms of aluminium phosphinate in combination with melamine cyanurate in glass-fibre-reinforced poly(1,4-butylene terephthalate)," Macromolecular Materials and Engineering, vol. 293, no. 3, pp. 206-217, 2008.

[9] T. S. Ma and G. Zuazaga, "Micro-kjeldahl determination of nitrogen A new indicator and an improved rapid method," Industrial and Engineering Chemistry, vol. 14, no. 3, pp. 280-282, 1942.

[10] Association of Official Analytical Chemists, Official Methods of Analysis, 10th edition, 1965.

[11] D. H. Copp, "Simple and precise micromethod for EDTA titration of calcium," The Journal of Laboratory and Clinical Medicine, vol. 61, pp. 1029-1037, 1963. 

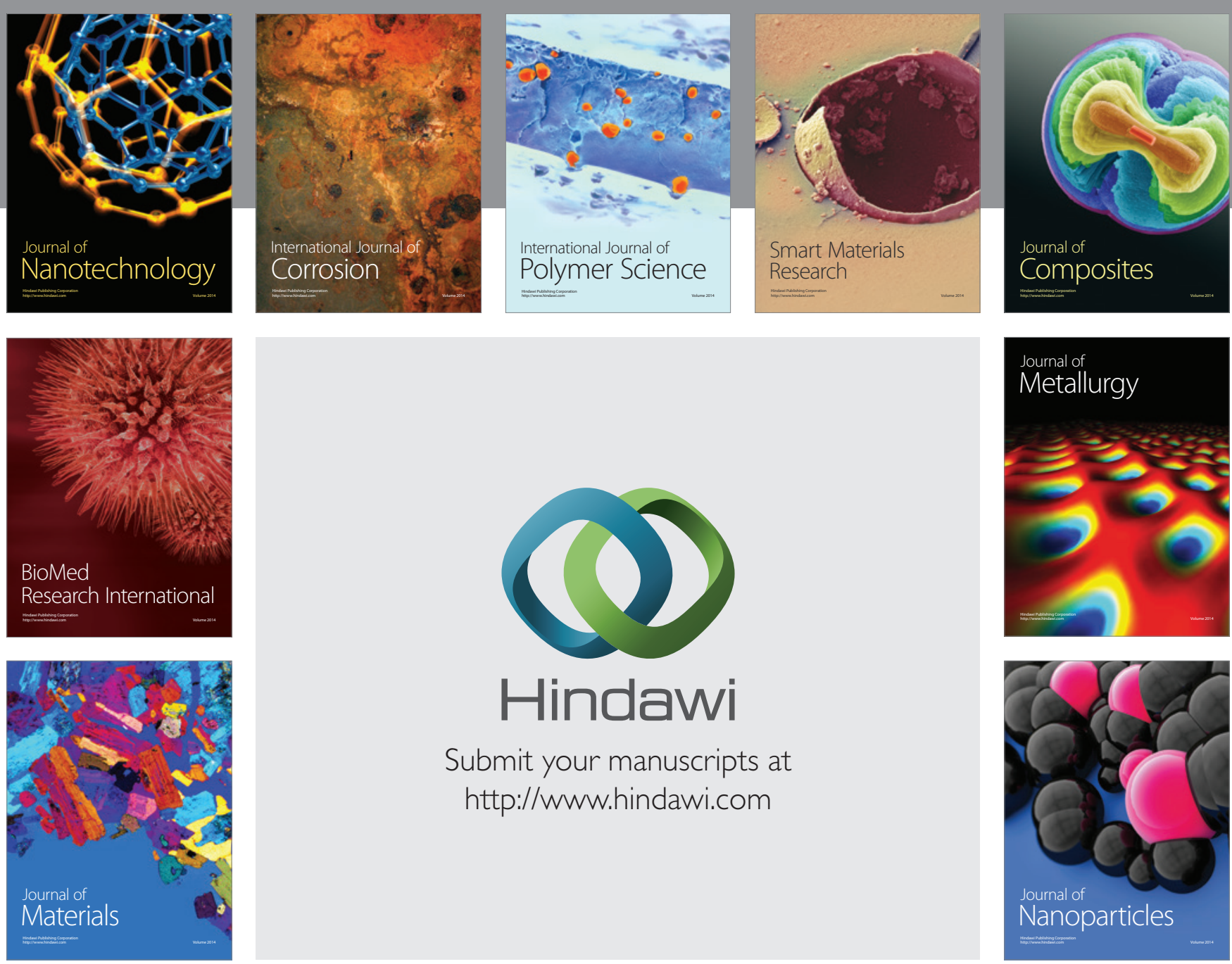

Submit your manuscripts at http://www.hindawi.com
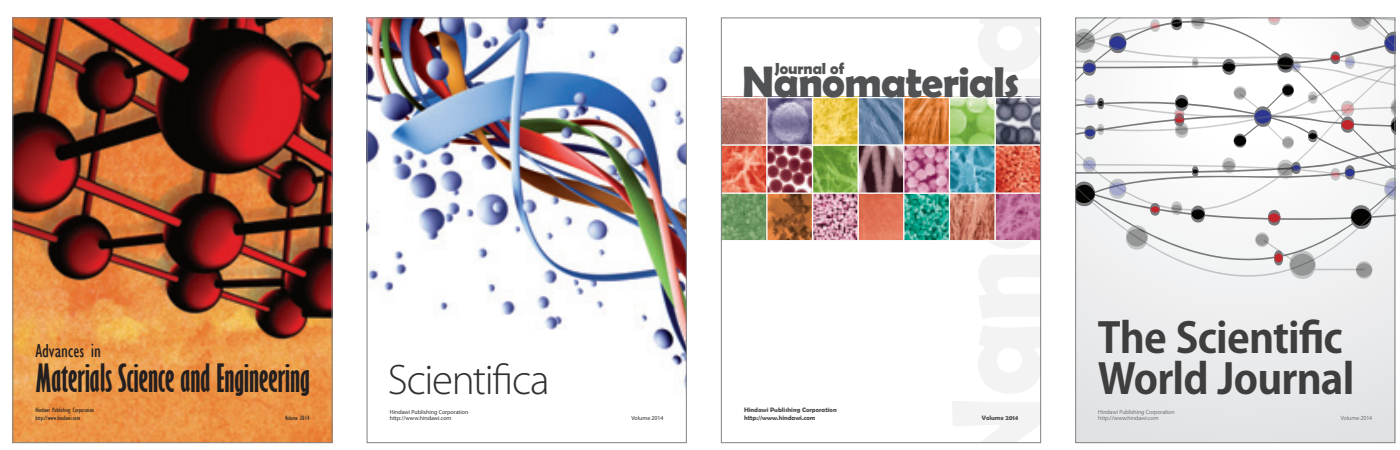

\section{The Scientific World Journal}
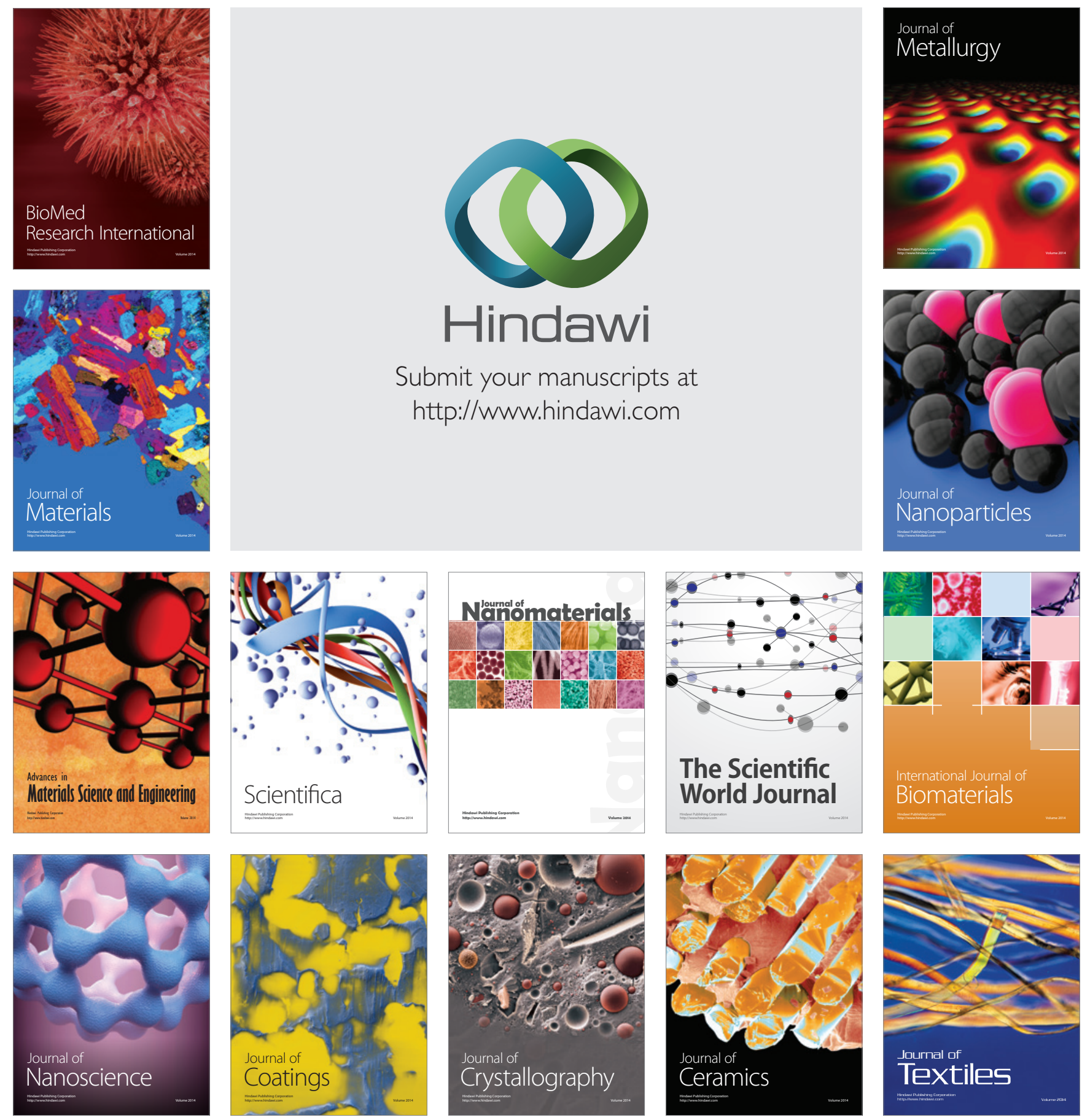